\title{
Correction to: Infectious Disease Management and Control with Povidone Iodine
}

Maren Eggers

Published online: August 22, 2019

(C) The Author(s) 2019

Correction to: Infect Dis Ther

https://doi.org/10.1007/s40121-019-00260-x

In the original publication, Figure 1 was incorrectly published. The correct Figure 1 is given here.

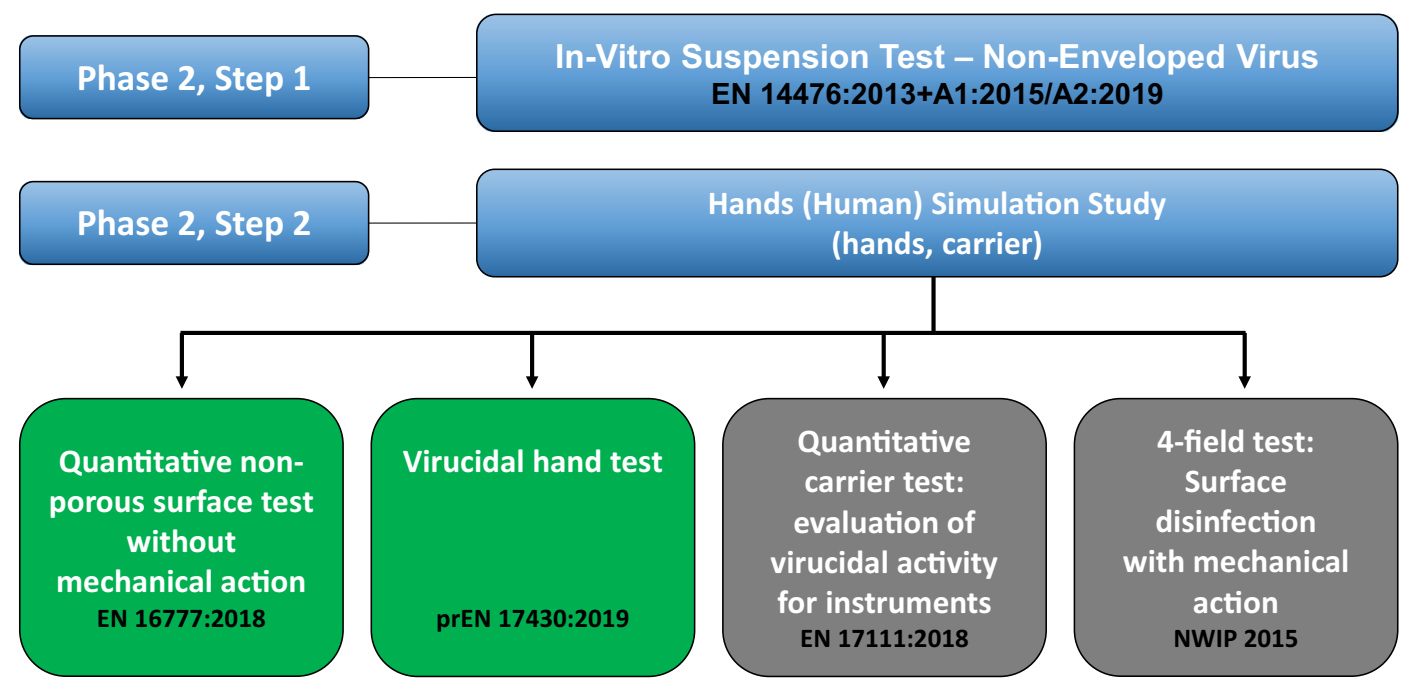

The original article can be found online at https://doi. org/10.1007/s40121-019-00260-x.

\section{Eggers ( $\square)$}

Labor Prof Gisela Enders MVZ GbR, Stuttgart, Germany

e-mail: eggers@labor-enders.de

Open Access. This article is distributed under the terms of the Creative Commons Attribution-NonCommercial 4.0 International License (http://creativecommons.org/licenses/ by-nc/4.0/), which permits any noncommercial use, distribution, and reproduction in any medium, provided you give appropriate credit to the original author(s) and the source, provide a link to the Creative Commons license, and indicate if changes were made. 